\title{
Metáforas para interação discursiva no ensino de ciências
}

Metaphors for discursive interaction in science teaching

\author{
Mariana Fernandes Silva ${ }^{1}$ \\ Carlos Eduardo Laburú \\ Osmar Henrique Moura da Silva ${ }^{3}$
}

\section{Resumo}

Este trabalho tem como objetivo investigar o uso de metáforas para provocar e sustentar o processo discursivo dialógico e de autoridade no conteúdo de Ciências relacionado à preservação da água. Dada essa função às metáforas, observa-se a construção de significados dos estudantes a partir da alternância desses dois gêneros discursivos. A coleta de dados foi dividida em duas etapas, nas quais a primeira prevalece o discurso dialógico e a segunda com predominância do discurso de autoridade. Os resultados obtidos seguem analisados também nessas duas etapas, cujos desempenhos dos estudantes se mostram razoáveis na construção dos significados pretendidos quando auxiliada esta forma discursiva pelo de uso das metáforas aqui empregadas.

Palavras chave: metáforas; interação discursiva; construção de significados; preservação da água.

\section{Abstract}

This work aims to investigate the use of metaphors to provoke and sustain the dialogical and authoritative discursive process in the content of Sciences related to the preservation of water. Given this function to metaphors, one can observe the construction of meanings of the students from the alternation of these two discursive genres. The data collection was divided in two stages, in which the first one prevails the dialogic discourse and the second with predominance of the discourse of authority. The results obtained are also analyzed in these two stages, whose performances of students are reasonable in the construction of the intended meanings when aided this discursive form by the use of the metaphors used here. Keywords: metaphors; discursive interaction; construction of meanings; preservation of water.

\footnotetext{
${ }^{1}$ Universidade Estadual de Londrina | mari_mmz@hotmail.com

${ }^{2}$ Universidade Estadual de Londrina | laburu@uel.br

${ }^{3}$ Universidade Estadual de Londrina | osmarh@uel.br
} 


\section{Introdução}

Pesquisas mostram que interações e discursos em sala de aula são elementos importantes para a aprendizagem do aluno (GALIETA, 2014; FIGUEIREDO; SEPULVEDA, 2014), mas pouco se discute como, porque, e para que ocorrem essas interações pela alternância de discursos de gêneros durante o diálogo. Com relação ao discurso e sua importância em sala de aula, Mortimer e Scott (2002, p. 284) afirmam que pouco se sabe a respeito de como os estudantes constroem significados, como as interações são produzidas em relação aos diferentes tipos de discurso e, ainda, como isso pode auxiliar a aprendizagem dos mesmos. Tendo em conta essa precária atenção à importância central do discurso de professores e alunos para a construção de novos significados pelos aprendizes, tanto entre professores, professor-formador e investigadores da área, três pontos em particular seguem destacados à perspectiva da presente pesquisa: Um deles se refere ao discurso, alvo de estudos embasados nas ideias de Mortimer e Scott (2002) acerca da relação professor-aluno na construção de conceitos científicos e a influência da linguagem nesse processo; Outro ponto diz respeito às metáforas, as quais são utilizadas como relevantes signos artísticos a fim de provocar o discurso; O último ponto relaciona-se à noção de preservação de água, questão levantada dentro da área de educação ambiental, considerada tema atual e potencialmente geradora de discussões. Nesse contexto, por meio de uma ferramenta analítica (MORTIMER e SCOTT, 2002) mais à frente detalhada, pretendese aqui averiguar a construção de significados gerados pela utilização de metáforas que visam auxiliar a estratégia pedagógica do discurso dialógico e de autoridade.

\section{Fundamentação teórica}

\section{Interação discursiva}

A ideia de que a natureza da linguem é social, constitui os sujeitos e por eles é constituída, foi defendida por Bakhtin (2003) ao explicar que pela atividade discursiva, o homem, ser social, age e reage interativamente no mundo. Dessa maneira, a linguagem em sua complexidade social, histórica, ideológica, reflete e refrata as práticas culturais do homem nos contextos de suas atividades sociais. Assim, com essa ideia dialógica da linguagem, Bakhtin aproxima língua (discurso) e vida vivida. Segundo Bakhtin (1997), aprendemos a falar quando aprendemos a elaborar enunciados. Desta maneira, entende-se que o aluno aprende à medida que pode explicitar o seu pensamento, tendo oportunidade de familiarizar-se com o uso de uma linguagem característica da cultura científica (DRIVER, NEWTON e OSBORNE, 1999). Ainda para Bakhtin (1992), as palavras não são "inocentes", desprovidas de um sentido ideológico, mas uma "arena" onde ocorrem os confrontos de valores sociais contraditórios e os conflitos de classe, as relações de poder e dominação. Enfim, uma adaptação ou resistência às normas pré-estabelecidas.

Educacionalmente, portanto, em certos momentos torna-se prudente "dar voz ao aluno" para que ele tenha a oportunidade de expressar seu modo de pensar, justificando-se com argumentações que muitas vezes, e inclusive por força do aprendizado, são próprias do pensamento científico. Esta argumentação seria o esclarecimento intencional durante ou após a elaboração de um raciocínio, caracterizando uma maneira de aproximar o pensamento científico do cotidiano (Capecchi e Carvalho, 2001). Conforme Candela (1993) e 
Scott (1997), o estudante adquire novas formas de falar, próprias do professor, quando participa de interações verbais durante as aulas de Ciências.

As interações discursivas em sala de aula de ciências têm sido objeto de estudo de diversas pesquisas, tanto no que se refere aos aspectos do discurso do professor como entre os estudantes ou na interação entre ambos. A sala de aula caracterizou-se como um espaço para a comunicação,reestruturação de significados, articulação de ideias e lugar de possíveis metáforas e analogias que podem levar o aluno a pensar e refletir, e que, a partir de uma interação discursiva, podem surgir pontos de vista relacionados aos conceitos espontâneos que o aluno traz consigo.

Segundo Mortimer e Scott (2002), os significados são vistos como polissêmicos e polifônicos criados na interação social e então internalizados pelos indivíduos. Na estrutura analítica elaborada por Mortimer e Scott (2002) para analisar o discurso em sala de aula, os fenômenos da linguagem são compreendidos a partir de uma abordagem comunicativa oriunda da obra de Bakhtin (1986); Bakhtin/Voloshinov (1997) com o objetivo de examinar como os professores dão suporte ao processo de construção de significados, pelos estudantes, em aulas de ciências, e como os diferentes tipos de discurso podem auxiliar a aprendizagem dos estudantes.

Para Bakhtin (1991), a cognição depende das condições sociais de produção das interações e não depende apenas do indivíduo, pois o sentido da palavra não está contido nela, mas está inserido no contexto em que ela acontece, ou seja, o significado é fruto de um processo construído no contexto das enunciações concretas, onde cada palavra ou enunciado está ligado a outro que o antecede e que o precede nesse contexto e cujos elos provocam e determinam respostas e ressonância dialógica, ou seja, o diálogo é o meio propício para a aproximação entre as vozes dos integrantes. Compreender o enunciado significa empreender ações dialógicas, em que uma palavra contrapõe-se a outra. Na interação sociocultural, o professor deve apresentar o conhecimento sistematizado a seus alunos. Segundo Scott (1997), nas aulas diárias e costumeiras de ciências, a fala do professor tem inegavelmente a função de autoridade para ensinar conceitos científicos.

Dentro das considerações acima, Mortimer e Scott (2002) defendem a alternância de dois tipos de discurso no contexto social da sala de aula, ou seja, um ritmo do discurso nas aulas salientando a importância dessa alternância para desenvolver, no debate e na exploração de ideias, o pensamento conceitual, no aluno. Indicam (ibid.), ainda, que a análise do discurso em sala de aula é fundamental para melhor desenvolver a argumentação dos alunos. A alternância dos discursos, denominados dialógico e de autoridade, indica também a complexidade e a relevância da comunicação contextualizada para o espaço dinâmico interativo da sala de aula, além de valorizar os aspectos pedagógicos do professor, como dirigente desse processo. Processo este cujo papel está em mediar o conhecimento para que os alunos possam, a partir daí, tirar conclusões de conceitos trabalhados e validados em sala de aula, utilizando-os de maneira que possam servir-Ihes de base para que outros e novos conceitos possam ser internalizados. Em síntese, o discurso dialógico e de autoridade geralmente caracteriza-se como uma forma de interação entre professor/aluno ocorrida na sala de aula (ibid.). Por esse referencial, a interação, marcada pela alternância de gêneros, ou seja, com o discurso dialógico alternado com o discurso de autoridade, é fundamental para que ocorra a aprendizagem do aluno acerca de determinado conteúdo. 
Mais especificamente, o discurso de autoridade é caracterizado como sendo aquele em que uma única voz é considerada. Isso quer dizer que o professor, deve ser a voz de autoridade dentro da sala de aula, pois cabe a ele o papel de direcionar as opiniões manifestadas pelos estudantes para a direção que deseja, ou seja, para o assunto que deseja trabalhar e discutir. O professor pode, com o discurso de autoridade, considerar as ideias dos alunos apenas na dimensão científica, segundo o que a ciência coloca como sendo o correto. Já o discurso dialógico, basicamente, por derivação, poderia ser entendido como aquele no qual há o diálogo, mas que não pode ser confundido com o diálogo que ora aconteça no discurso de autoridade, mencionado acima. No discurso dialógico pode ocorrer a expressão de diferentes pontos de vista, ainda que somente um venha a ser considerado. Nesse sentido, cabe ao professor o papel de acatar e socializar diferentes opiniões, por isso é necessário que se entenda que a dialogicidade relaciona-se, diferentemente do que se possa imaginar, com a atitude de acatar e socializar as diferentes vozes e opiniões em uma aula (MORTIMER E SCOTT, 2002).

Embora uma alternância desses dois gêneros discursivos seja algo pedagogicamente desejado e que deveria ocorrer de maneira natural numa aula (MORTIMER E MACHADO, 2000), na esmagadora maioria das vezes, mesmo professores conscientes de tal importância esbarram em dificuldades para realizar essa dinâmica discursiva. As dificuldades que prontamente aparecem são de como provocá-la e em que momento, e, sendo isso superado, fica a questão de como sustentar o gênero discursivo dialógico frente ao de autoridade por um tempo suficiente para desencadear reflexão e argumentação entre os aprendizes a respeito do conteúdo estudado. Por consequência, ao tentarem praticar uma dinâmica discursiva dialógica e de autoridade, os professores tendem a desequilibrá-la, pendendo predominantemente ${ }^{4}$ para o discurso de autoridade, e assim levam o discurso dialógico ser rapidamente abandonado em virtude de não conseguirem mantê-lo com os alunos por um tempo necessário ao aproveitamento pedagógico almejado. Por tal problemática existente nesse importante viés educacional, a próxima subseção caracteriza o uso das metáforas, que neste trabalho são atreladas estrategicamente visando potencializar essas interações discursivas em favor da construção cognitiva dos aprendizes.

\section{Metáforas}

A metáfora era definida na Retórica Antiga, segundo Edward Lopes (1986, p.25), como uma comparação abreviada, elíptica, concebida nos termos de uma figura do plano de conteúdo resultante de uma comparação entre dois termos, A e B, tomados como impropriamente semelhantes entre si, em que A seria o termo a definir - o comparado - e B, o comparante que o define a partir de um fundamento (algo comum a A e B) impróprio, com ausênsia da partícula comparativa - como, qual, tal, tal como, entre outras. Essa ideia levava ao entendimento de que a comparação ficaria mais clara, de caráter mais corriqueiro, mais fácil de entender. Ainda de acordo com Lopes (1986, p.25), isso era algum tipo de grau zero da linguagem, ao passo que a metáfora, que dela sairia por elipse do operador da comparação, seria por isso mesmo mais obscura ou misteriosa e, portanto, mais apta para expressar a intuição poética, com toda a sua carga de estranhamento. Certamente, é

\footnotetext{
${ }^{4}$ E por hábito de conviver muitos anos com ela.
} 
possível que a origem da assimilação do caráter poético do discurso com a propriedade metafórica da linguagem tenha surgido a partir dessa época. Para Aristóteles, o uso da metáfora era considerado a marca dos gênios. Usava-se tal recurso para facilitar o estudo e a compreensão de temas considerados complexos. Ele foi considerado o criador da concepção clássica da metáfora, a qual ficou conhecida como interpretação comparatista. Ressalta Rodriguez (1999, p. 1) que na retórica clássica "a função e origem da metáfora é de proporcionar prazer estético ao entendimento".

Sabido que as metáforas são amplamente utilizadas no ensino, inclusive nos conteúdos de Ciências, há uma preocupação das pesquisas acerca das formas mais adequadas para suas utilizações, e também em definir como ocorrem esses processos. (WILBERS; DUIT, 2001; GLYNN et al., 1998; VENVILLE; TREAGUST, 1996) Na visão construtivista, a aprendizagem se faz por meio de um processo de construção a partir do conhecimento previamente adquirido. Com isso, é correto dizer que a aprendizagem é um processo que emprega o familiar para compreender o que não é familiar, ou seja, o desconhecido. Em razão disso, enfatizasse a importância do significado do emprego das metáforas dentro de uma abordagem construtivista. Para Duit (1991), estudos sobre concepções alternativas, representações prévias dos alunos em relação aos conceitos científicos para serem compreendidos é necessário que esse se de através do emprego de metáforas em áreas que não são familiares a eles. Isto reforça a ideia de que os conteúdos que precisam ser explorados pelo professor, no caso da presente pesquisa, os conteúdos relacionados à preservação da água, utilizem as metáforas para explorar assuntos que estejam poucos "íntimos" dos estudantes.

Indo além da consideração da definição de metáfora nada mais do que uma comparação sem o uso da partícula comparativa, em que as semelhanças aparecem implicitas, cabe ainda dizer que se faz aqui uma coerente abordagem semiótica relacionando metáfora como signo artístico, que pode ter função estética e função semântica. A função semântica possui caráter lógico, com respostas ativas para fins explícitos, possui significado preciso, é um signo científico único com o objetivo de facilitar a comunicação. Nesse sentido, as metáforas com função semântica estariam representadas, por exemplo, por placas de trânsito. Já a função estética proporciona uma inesgotabilidade dos sentidos, visto que seus significados podem variar até para o mesmo receptor, não demanda resposta única ou exata, e pode agregar diferentes significados. Assim sendo e pelo objetivo da presente pesquisa, selecionam-se pedagogicamente metáforas com função estética por admitir que ao se deparar com respostas exatas e diretas, como signos artísticos de função semântica proporcionam, não se permite resolver o problema. Tendo em conta que o processo metafórico ocorre muitas vezes de maneira espontânea pelo professor, seja ele em momento oportuno ou não, ressalta-se que neste trabalho as metáforas são utilizadas de maneira consciente.

\section{Meio Ambiente: preservação da água}

A Educação Ambiental, segundo Carvalho (2006), tem assumido nos últimos anos o grande desafio de garantir a construção de uma sociedade sustentável, em que se promovam, na relação com o planeta e seus recursos, valores éticos como cooperação, solidariedade, generosidade, tolerância, dignidade e respeito à diversidade. As reflexões sobre os problemas ecológicos nos chamam a atenção para questões vitais. Essa chamada aponta para a crise civilizacional de nossos dias e tem por finalidade oferecer elementos 
para se criar novas formas de relacionamento ecológico e de sustentação da vida no planeta. A partir das discussões mundiais sobre essa temática, Boff (2009) considera a ecologia em quatro aspectos, sendo eles a ecologia ambiental, cuja preocupação com o meio ambiente visa a qualidade de vida, a preservação das espécies em extinção, e a permanente renovação do equilíbrio da natureza, que segundo esse aspecto aborda-se neste momento a importância da água para a manutenção de todo ecossistema, em que a grande questão está no cuidado da vida no e do planeta. O cuidado consiste em: não continuar, de forma irresponsável, poluindo as águas e nem desperdiçando com hábitos errados. Por sua vez, a ecologia social não busca o cuidado do meio ambiente, mas do ambiente inteiro, pois integra o ser humano, a sociedade e a natureza, como partes diferenciadas da ecologia, ou seja, não se preocupa apenas com a beleza da cidade, com suas praças atrativas, mas priorizam as condições dignas para o desenvolvimento da vida, que no caso específico desse trabalho está destacado o saneamento básico, uma vez que se relaciona com a qualidade da água que chega para a população. Já a ecologia mental diz que o problema da destruição da terra não se encontra apenas no tipo de sociedade atual, mas no tipo de mentalidade que ainda vigora entre os seres humanos, e sugere que para a crise ecológica ser superada, exige novo perfil de cidadãos, com nova mentalidade, mais sensíveis, mais cooperativos e solidários, que de acordo com o presente artigo buscamos na tentativa de sensibilizar os estudantes a ponto de mudarem seu comportamento e atitudes em relação a água potável. Por fim, a ecologia integral, parte de uma nova visão da Terra e dos seres humanos, onde, para Boff (2009), o ser humano é Terra enquanto sente, pensa, ama, chora e venera e por isso acreditamos que para discutir qualquer assunto relacionado com o meio ambiente, especialmente o assunto em questão preservação da água - é indispensável a associação ambiental, social e mental.

\section{Procedimentos metodológicos}

Trata-se de uma pesquisa denominada estudo de caso, em que os dados foram categorizados de acordo com a análise textual qualitativa (MORAES, 2005). Por convenção, segue apresentada neste trabalho a coleta de dados dividida em duas etapas com respectivas análises, nas quais a primeira ocorreu com predominância do discurso dialógico e a segunda com predominância do discurso de autoridade. Os participantes da pesquisa são estudantes do sexto ano do Ensino Fundamental II, de uma escola pública do município de Santa Cruz do Rio Pardo - SP. Os dados foram coletados em 2012, mas recentemente analisados, com estudantes possuindo idades entre 11 e 13 anos.

\section{Ferramenta analítica}

A estrutura analítica da ferramenta divulgada por Mortimer e Scott (2002), a qual será utilizada para analisar as interações e a produção de significados na aula de ciências a respeito da preservação da água, é baseada em cinco aspectos inter-relacionados, que focalizam o papel do professor e são agrupadas em termos de focos de ensino (intenção do professor e conteúdo), abordagens (abordagem comunicativa) e ações (padrões de interação e intervenções do professor). Estes aspectos inter-relacionados podem ser assim sintetizados: 
1. Intenções do professor - Diz respeito à intenção do professor, ou seja, o que o professor pretende para ministrar sua aula. A intenção do professor está relacionado então ao foco.

2. Conteúdo - Corresponde ao assunto que será trabalhado em sala de aula, podendo este ser transmitido de modo explicativo, generalizado ou por descrição.

3. Abordagem comunicativa - Relaciona-se à abordagem comunicativa, a qual é central na estrutura analítica, fornecendo a perspectiva sobre como o professor trabalha, as intenções e o conteúdo do ensino por meio de diferentes intervenções pedagógicas que resultam em diferentes padrões de interação. Mortimer e Scott (ibid.) destacam quatro classes de abordagem comunicativa, que são definidas por meio da caracterização do discurso entre professor e alunos, ou entre alunos, em termos de duas dimensões: discurso dialógico ou de autoridade; discurso interativo ou não interativo. Nesta pesquisa estão analisados apenas os discursos interativos dialógico e de autoridade.

4. Padrões de interação - O quarto aspecto da ferramenta analítica são os padrões de interação, os quais se encontram "I" (início do diálogo), normalmente estabelecido por meio de uma pergunta do professor, "R" (resposta do aluno), "A" (avaliação do professor) e " $F$ " (feedback), normalmente estabelecido pelo professor de modo que o aluno repense a respeito do que foi dito e formule melhor sua resposta. Cabe dizer que o padrão de interação mais comum está na tríade I-R-A (Iniciação do professor, Resposta do aluno, Avaliação do professor), embora outros padrões também possam ser observados.

5. Intervenções do professor - O quinto aspecto da ferramenta analítica especifica as formas de intervenções pedagógicas do professor. Diferente das intenções que estão relacionadas ao foco do professor, as intervenções relacionam-se às ações, ou seja, como o professor age (intervém) na interação.

\section{Resultados e discussão}

Nesta seção, cada resultado procede de uma figura que inicialmente fora apresentada aos estudantes para reflexão, caracterizando, a partir dela, os diálogos ocorridos seguidos de uma descrição dos mesmos na qual se indicam os aspectos mencionados anteriormente, também reunidos num quadro representativo da análise das interações no episódio educacional. Por fim, faz-se uma síntese dos significados construídos.

\section{Primeira etapa: Predominância do discurso dialógico}

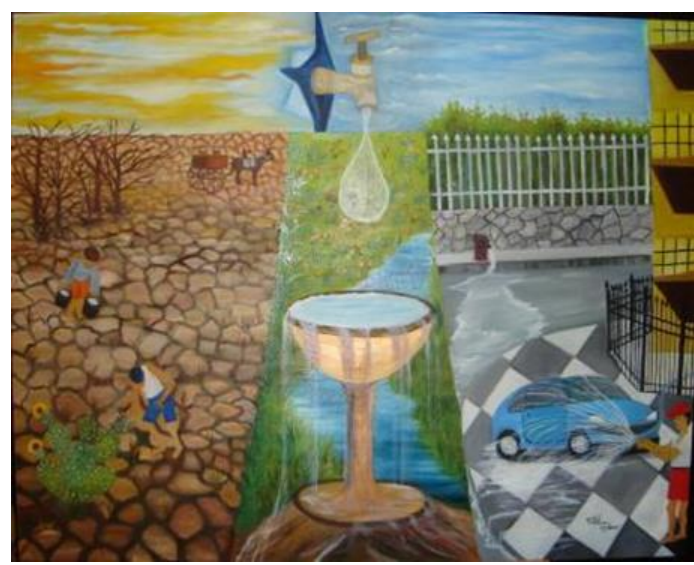

Figura 1: O contraste. Fonte: secretariadeculturadepoa.blogspot.com.br 
1-Professora- O que vocês veem nesta imagem?

2-Todos se manifestam ao mesmo tempo.

3-Professora- Pessoal, um de cada vez, levantem as mãos.

4-Aluno (b)- Uma pessoa com a mangueira ligada lavando o carro.

5-Aluno (a)- A mangueira vazando.

6-Aluno (c)- Plantação, árvore.

7-Professora- A mangueira ligada, vazando, uma pessoa lavando o carro, árvores, plantas, o que mais vocês conseguem ver?

8-Aluno (a)- De um lado vida, plantações, e do outro, seca.

9-Aluno (e)- É! Folhas secas têm também umas pessoas mais magrinhas desse lado.

10-Professora- Então de um lado há vida e do outro tudo está seco?

11-Todos se manifestam dizendo sim.

12-Professora- Vocês também disseram que, além de folhas secas, as pessoas estão mais magrinhas desse lado (apontando), né?

13-Aluno (e)- Sim, porque desse lado que as pessoas estão magrinhas, elas estão secas, desnutridas, porque não possui água.

14-Professora- $O$ que mais vocês veem?

15-Aluno (b)- Também tem a torneira pingando.

16-Aluno (e)-É! Tem uma torneira com uma gota caindo

17-Professora- E essa gota está caindo onde? O que é isso (apontando)?

18-Aluno (b)- É um chafariz.

19-Aluno (d)- É uma fonte?

20-Professora- Uma fonte! O que será que isso está querendo dizer?

21-Aluno (e)- Está querendo mostrar o desperdício

22-Aluno (d)- Professora, é como se a água fosse a fonte da vida, sem água não existem plantas, é tudo seco.

23-Professora- A água como fonte da vida, nesta figura está bem evidente o contraste da abundância de água com a seca.

24-Todos concordam.

25-Aluno (e) - De um lado desperdiçando água e do outro faltando.

26-Professora- Isso! Muito bem, agora vamos passar para a próxima.

A professora, na fala 1, convidou os estudantes a exporem suas opiniões sobre o que visualizaram na imagem, com a intenção de explorar as ideias dos estudantes a respeito da importância da água para a vida. Obteve, como respostas dos alunos "b", "a" e "c", descrições da imagem exposta, observadas respectivamente na sequência (falas 4, 5 e 6). Propositadamente, a professora reproduziu as respostas dos estudantes na fala 7. Nesse momento, pôde-se considerar um padrão I-R-A, pois a professora iniciou a interação com uma pergunta (I), os alunos responderam (R), e, ao repetir as respostas, a professora as avaliou como corretas (A). Em seguida, o aluno "a" se manifestou, apontando na fala 8 que há uma diferença de um lado para o outro na figura, dizendo que num lado aparece vida, plantações, e noutro lado tudo está seco. O aluno "e", na fala 9, concordou com o aluno "a" e acrescentou que do lado onde está tudo seco também possui umas "pessoas magrinhas". A professora, então, em um feedback na fala 10 e 12, repetiu a ideia dos alunos "a" e "e" em forma de pergunta para que eles formulassem melhor sua resposta, e a fim de desenvolver a "estória científica", focalizando a atenção para a importância da "água". Seguidamente, o aluno "e", na fala 13, mencionou a "água" como principal motivo pela diferença de um lado para o outro da figura. Novamente, a professora perguntou na fala 14 o que mais os alunos 
vêem na figura (I) (Sugestão à frase anterior: Novamente, na fala 14, a professora busca direcionar uma maior atenção dos alunos à figura, a fim de que eles permaneçam refletindo e indicando detalhes (I)). Eles apontaram nas falas 15 e 16 que há uma gota caindo de uma torneira (R). A professora repetiu o que eles disseram (A) e, com a intenção de os alunos falarem da fonte, usou do discurso de autoridade para direcionar e formular uma pergunta (fala 17), que levasse à resposta esperada (I). Os alunos "b" e " $\mathrm{d}$ ", respectivamente, responderam: um chafariz (fala 18) e uma fonte (fala 19) (R). Logo (fala 20), a professora selecionou a resposta 19, dita pelo aluno " $\mathrm{d}$ " (A), descartando, com isso, a resposta 18, e prosseguiu com a pergunta a respeito do significado da existência da fonte (I). Nas falas $21 \mathrm{e}$ 22, os alunos " $e$ " e " $d$ ", expressaram a ideia a respeito do desperdício e ressaltaram a importância da água como "fonte da vida" (R). Em 23, a professora confirmou a resposta do estudante, repetindo a ideia da "água como fonte de vida" (A). E, por fim, o aluno "e", na fala 25, apontou a água como causadora do contraste, no qual de um lado há o desperdício e do outro há água em abundância.

Tabela 1- Quadro representativo da análise da interação 1.

\begin{tabular}{|l|l|}
\hline Intenções da professora & $\begin{array}{l}\text { Explorar as ideias dos estudantes. Desenvolver a "estória científica", } \\
\text { focalizando a atenção para a importância da água. }\end{array}$ \\
\hline Conteúdo & $\begin{array}{l}\text { Descrição de um lugar onde há água em abundância com a } \\
\text { descrição de um lugar onde a água é escassa. }\end{array}$ \\
\hline Abordagem & $\begin{array}{l}\text { Interativa dialógica (com intervenções de autoridade pela professora } \\
\text { nas falas 17 e 20). }\end{array}$ \\
\hline Padrões de interação & $\begin{array}{l}\text { Maior parte da interação segue o padrão I-R-A, porém ocorre } \\
\text { feedback nos momentos } 10 \text { e 12. }\end{array}$ \\
\hline Formas de Intervenção & $\begin{array}{l}\text { Repetir as ideias dos estudantes; Selecionar as respostas dos } \\
\text { estudantes; Formular questões instrucionais. }\end{array}$ \\
\hline
\end{tabular}

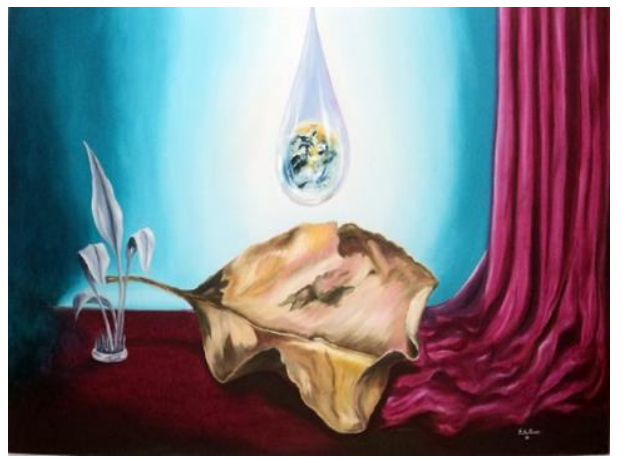

Figura 2: A gota. Fonte: semanadeartecarioca.arteblog.com.br

1- Professora - E essa figura?

2- Todos falam ao mesmo tempo.

3- Um aluno fala no fundo - É uma folha desnutrida!

4- Outro diz - É uma folha seca!

5- Professora - Então... uma folha seca, desnutrida, o que mais estão vendo?

6- Vários dizem - Uma gota!

7- Aluno (e) - Uma gota de esperança.

8- Professora - Uma gota, uma gota de esperança.

9- Aluno (c) - Tem alguma coisa verdinha dentro da folha. 
10- Professora - Uma coisa verdinha? Isso? (apontando).

11- Aluno (d) - É, Professora! É como se a gota fosse trazer vida para folha.

12- Professora - Então esse verdinho dentro da gota está representando a vida, como se a gota fosse trazer vida para a folha?

13- Aluno (e) - Por isso que eu disse que é a gota da esperança.

14- Professora - Então, esta figura mostra uma gota caindo numa folha seca. E esta gota de água está representando não apenas a vida, como a esperança para a folha seca?

15- Vários alunos - Sim!

16- Aluno (e) - Isso dentro da gota está representando o mundo, a vida, como se todos dependessem da água.

17- Aluno (d) - E quando ela cai sobre a folha seca é como se tivesse trazendo uma vida nova para a folha, porque ela está seca, porque está sem água.

18- Professora - Muito bem, então a figura está mostrando a importância que a água representa para a vida não só dessa folha, mas como a vida do mundo, pois como vocês mesmos disseram, dependemos dela para viver.

A interação novamente se iniciou com uma pergunta da professora em relação ao que os alunos poderiam ver na figura, pois a intenção da professora ainda se manteve na exploração das ideias dos alunos, estabelecendo com isso um padrão I-R-A. Foram obtidas como respostas nas falas 3 e 4 "uma folha desnutrida" e "uma folha seca", respectivamente. A professora, na fala 5, apenas repetiu as duas respostas e perguntou mais uma vez a respeito do que mais estavam vendo. O diálogo ficou estabelecido em sua maior parte, nesse padrão, I-R-A, com uma pergunta da professora, a resposta do aluno e a avaliação da professora por meio da repetição das respostas. Ao se deparar com a resposta na fala 9, "tem uma coisa verdinha dentro da folha", por meio de um feedback, a professora mantém na fala 10 a repetição da resposta em forma de pergunta para que o aluno explicasse melhor o que seria "essa coisa verdinha", na intenção de que o estudante relacionasse a resposta à importância da água com a vida. Já os alunos "e" (fala 16), e "d" (fala 17) conseguem explicar perfeitamente o que a professora pretendia, pois relacionaram a água como algo não apenas para manter a vida daquela folha, e sim como responsável pela manutenção da vida de todo o planeta. Para encerrar a interação da quarta imagem, a professora organizou as respostas fornecidas pelos estudantes e concluiu melhor a proposta da figura, baseada apenas nas respostas dos alunos.

Tabela 2: Quadro representativo da análise da interação 2.

\begin{tabular}{|l|l|}
\hline Intenções da professora & $\begin{array}{l}\text { Explorar as ideias dos estudantes, focalizando a importância da } \\
\text { água para a manutenção da vida no planeta. }\end{array}$ \\
\hline Conteúdo & Descrição de uma folha seca. \\
\hline Abordagem & Interativa dialógica. \\
\hline Padrões de interação & IRA, com feedback em 10. \\
\hline Formas de intervenção & $\begin{array}{l}\text { Repetir as ideias dos estudantes; Organizar as respostas dos } \\
\text { estudantes. }\end{array}$ \\
\hline
\end{tabular}




\section{Síntese da construção dos significados}

De acordo com a análise das interações referentes às figuras 1 e 2 da primeira etapa, na qual ocorre a predominância do discurso dialógico, pôde-se constatar que a intenção da professora com a escolha das imagens se manteve na exploração das ideias dos estudantes, focalizando a importância da água com a manutenção da vida do planeta, ou seja, conduzindo os alunos ao significado de que a água é essencial para a vida. Pela análise da interação da primeira figura, evidenciou-se a construção de significados por meio da interpretação correta dos alunos ao destacarem a problemática da escassez da água e evidenciarem o contraste entre a seca com um lugar onde a água é desperdiçada, e mais ainda ao direcionarem o papel da água para a existência da vida. Já na segunda figura, a construção de significados pôde ser notada quando os estudantes destacaram que só pode haver plantações e vida onde existe água, além de enfatizarem a importância de não desperdiçá-la.

\section{Segunda etapa: predominância do discurso de autoridade}

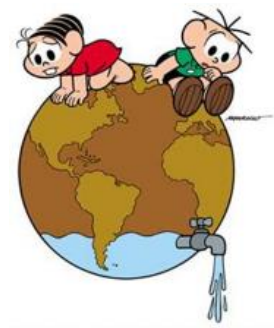

Figura 3: O mundo esvaziando. Fonte: portaldoprofessor.mec.gov.br

1- Professora - E esta imagem?

2- Todos riem.

3- Professora - Pessoal, vamos devagar, um de cada vez falando o que está vendo na imagem.

4- Aluno (c) - $O$ mundo.

5- Professora - O mundo, o que mais vocês estão vendo?

6- Aluno (e) - O Cascão e Mônica tristes.

7- Professora - O Cascão e a Monica tristes. Então deve estar acontecendo alguma coisa ruim para eles estarem assim, certo? Por que vocês acham que eles estão tristes?

8- Aluno (e) - Porque estamos desperdiçando água.

9- Professora - O que mostra na figura o nosso desperdício?

10- Aluno (e) - A torneira aberta.

11- Professora - Então a torneira aberta está mostrando que estamos desperdiçando água e o Cascão e a Mônica estão tristes por isso?

12- Todos se manifestam dizendo sim.

13- Professora - Na imagem dá para ver o que está acontecendo no mundo por causa do desperdício?

14- Aluno (b) - Está acabando a água.

15- Aluna (d) - Professora, está mostrando que está acabando a água do planeta, por isso o Cascão e a Mônica estão tristes! Porque estamos desperdiçando.

16- Professora - Isso, muito bem, exatamente. A imagem mostra a água acabando, pelo fato da torneira estar aberta, e o Cascão e Mônica estão tristes por isso. 
A primeira figura escolhida para compor a fase na qual prevaleceu o discurso de autoridade iniciou com uma pergunta da professora com a intenção de explorar as ideias dos alunos, logo, o aluno "c" responde na fala 4: "o mundo". A professora, na fala 5, repetiu a resposta do aluno, validando sua ideia, e novamente faz outra pergunta, estabelecendo com isso um padrão I-R-A, pois novamente outro aluno respondeu na fala 6 , e a professora repetiu o que foi dito pelo estudante, validando sua resposta em 7 . Porém, a intenção da professora foi de conduzir os alunos à construção de significados a respeito do desperdício da água. Por isso, a partir da fala 7, a professora utilizou o discurso de autoridade para formular questões instrucionais a fim de direcionar as respostas para o tema que gostaria que fosse discutido. Logo, na fala 9, o aluno já relacionou a figura à problemática do desperdício e, até o fim do diálogo, a professora apenas gerenciou as ideias dos alunos para confirmar o significado construído.

Tabela 3: Quadro representativo da análise da interação 3.

\begin{tabular}{|l|l|}
\hline Intenções da professora & $\begin{array}{l}\text { Explorar as ideias dos estudantes, focalizando o desperdício de água. } \\
\text { Criar um problema }\end{array}$ \\
\hline Conteúdo & $\begin{array}{l}\text { Descrição da presença da água e sua importância para a vida na terra } \\
\text { relacionada com o desperdício. }\end{array}$ \\
\hline Abordagem & Interativa de autoridade.(dialógica até a fala 6). \\
\hline Padrões de interação & I-R-A \\
\hline Formas de intervenção & $\begin{array}{l}\text { Selecionar as respostas dos estudantes; Repetir as ideias dos estudantes; } \\
\text { Formular questões instrucionais. }\end{array}$ \\
\hline
\end{tabular}

\section{Síntese da construção dos significados}

De acordo com a análise dos dados referentes às figuras 3 nesta segunda etapa, na qual ocorreu a predominância do discurso de autoridade, pode-se considerar que a intenção da professora, com a escolha da imagem, manteve-se na exploração das ideias dos estudantes, introduzir e desenvolver a "estória científica" a respeito de assuntos relacionados ao desperdício da água no planeta. Diante disso, a construção de significados ficou evidenciada na terceira figura, a exemplo da fala 15, quando destacada a problemática do desperdício.

\section{Considerações finais}

A proposta deste trabalho foi de investigar a utilização das imagens metafóricas para provocar e sustentar uma interação discursiva dialógica e de autoridade. Acerca das análises da construção de significados durante as interações, referentes ao tema preservação da água, pôde-se concluir que: i) De maneira geral, a pesquisa revelou fácil adaptação dos estudantes perante a estratégia didática a eles submetida, com uma participação relevante e discussão significativa; ii) Nessa razoável participação de estudantes na construção dos significados focados durante as interações, o emprego de imagens metafóricas mostrou-se eficiente para a sustentação do discurso dialógico e de autoridade em sala de aula; iii) Cabe ressaltar a importância da alternância desses gêneros discursivos, na medida em que se revelaram construções de significados tanto no discurso predominantemente dialógico como no discurso predominantemente de autoridade. Enfim, dentro da linha educacional 
construtivista, espera-se contribuir à formação continuada de professores e igualmente àqueles educadores que se identificam com essa proveitosa estratégia pedagógica.

\section{Referências}

BAKHTIN, M. Estética da Criação Verbal. São Paulo, Martins Fontes, 1997

BAKHTIN, M (V.N. Volochinov) Marxismo e filosofia da linguagem. Tradução de Michel Lauch e lara Frateschi Vieira. 6.ed. São Paulo: Editora Huritec 1992.

BAKHTIN, M. Speech Genres \& Other Late Essays. Ed. By Caryl Emerson and Michael Holquist, trans. By Vern W. McGee. Austin: University of Texas Press, 1986.

BOFF, L. Ética da vida a nova centralidade. Rio de Janeiro; São Paulo, Record, 2009.

CARVALHO, I. C. M. Educação ambiental: a formação do sujeito ecológico. 2.ed. São Paulo: Cortez, 2006.

CANDELA, A. La Construcción Discursiva de La Ciência em El Aula. Investigación em La Escuela, 21, 31-38, 1993.

CAPECCHI, M. C. V. de M. e CARVALHO, Anna M. P. Argumentação em uma aula de conhecimento físico com crianças na faixa de 8 a 10 anos. Disponível em Acesso em 30/04/2001 e 27/07/2004.

DRIVER, R. NEWTON, P, OSBORNE, J. The Place of Argumentation in ehe Pedagogy of School Science. Internacional Journal of Science Education, vol. 21, n. 5, 1999

DUIT, R. On the role of analogies and metaphors in learning science. Science Education, v.75, p.649-72, 1991.

FIGUEIREDO, P.S., SEPULVEDA. C. Multiculturalismo e interações discursivas nas salas de aulas de Ciências. Linguagens e discursos na educação em Ciências. Editora Multifoco, RJ., 2014.

GALIETA, T. Formação discursiva em textos de livro didático e de divulgação científica. Linguagens e discursos na educação em Ciências. Editora Multifoco, RJ, 2014.

GLYNN, S. M. et al. Teaching science with analogies: a resource for teachers and books authors. 1998. Disponível em: http://curry.edschool.virginia.edu.html

LOPES, E. Metáfora. Da retórica à semiótica. 2. Ed. São Paulo: Atual Editora, 1987.

MORAES, R. Mergulhos discursivos: análise textual qualitativa entendida como processo integrado de aprender, comunicar e inferior em discursos. Acta Scientiae, v.11, n.2, jul./dez. 2009 .

MORTIMER, E. F.; MACHADO, A. H. Anomalies and conflicts in classroom Discourse. Science Education, v. 84, p. $429-444,2000$.

MORTIMER, E. F.; SCOTT, P. Atividade discursiva nas salas de aula de ciências: uma ferramenta sociocultural para analisar e planejar o ensino. Investigações em Ensino de Ciências, v. 7, n. 3, p. 283-306, 2002. 
PITTMAN, K.M. Student-generated: another Way of knowing? Journal of Research in Science Teaching. v.36, n.1, p.1-22, 1999.

RODRÍGUEZ, M. V. Metáforas de interacción en Aristóteles. Disponível em: http://www.ucm.es/info/especulo/numero11/met_ari.html. Acesso em: 16/05/2012.

SCOTT, P. Teaching and Lerarning Science Concepts in the Classroom. Anais do Encontro sobre Teoria e Pesquisa em Ensino de Ciências, Belo Horizonte, 1997.

WILBERS, J.; DUIT, R. On the micro-structure of analogical reasoning: the case of undertanding chaotic systems. In: BEHRENDT, H. et al. Research in Science Education - Past, Present na Future. Dordrecht: Kluwer, 2001, p. 205-210. 